\title{
Quantitative Characterization of Alkyd Cure Kinetics with the Quartz Crystal Microbalance
}

\author{
Lauren F. Sturdy ${ }^{1}$, Alexander Yee ${ }^{1}$, Francesca Casadio ${ }^{2}$ and Kenneth R. Shull ${ }^{1}$ \\ ${ }^{1}$ Department of Materials Science and Engineering, Northwestern University, USA \\ ${ }^{2}$ The Art Institute of Chicago, USA
}

\begin{abstract}
The quartz crystal microbalance (QCM) was used to measure the time-dependent mechanical properties of an alkyd resin throughout the transition from its application as a liquid to the formation of a solid film. Three different regions of curing were observed, corresponding to solvent evaporation; early stage curing, where the mass increases as oxygen is incorporated into the film; and long-term curing, where the mass decreases as volatile compounds are released. Mechanical property changes obtained at $15 \mathrm{MHz}$ with the QCM were correlated with measurements at much lower frequencies utilizing traditional dynamic mechanical analysis. These mechanical property changes were in turn correlated to chemical changes tracked with Raman spectroscopy. From the temperature dependence of the curing process we obtain an effective activation energy of $4.1 \mathrm{kcal} / \mathrm{mol}$.
\end{abstract}

\section{Introduction}

Alkyd resins have been used as binders in paints since their development in the 1920s and have been used by artists for almost as long. These binders have properties similar to oil paints, but dry much faster. Alkyd paints can be touch-dry within 24 hours, while oil paints can take years to fully dry. A problem with alkyd paints is that they are known to become brittle with age [1]. This behavior raises concerns with regards to the longevity of these paint films and the works of art that contain them. A greater understanding of the mechanisms of alkyd film formation and what influences film properties will provide insights into how these materials can be stored and treated in order to preserve cultural heritage objects containing alkyd resins.

Alkyd resins are oil modified polyesters, which have a polyester backbone with fatty acid molecules attached. The number of fatty acid molecules along the backbone can be varied to change the properties of the coating. Alkyd resins used in artists' paints are usually long oil alkyds, which contain more than $60 \%$ oil by weight $[2,3]$. A model alkyd repeat unit is shown in Figure 1. This unit is for an alkyd that has a polyester backbone made of phthalic anhydride and glycerol with linoleic acid, which is found in linseed oil, as the representative fatty acid chain. The diacid and polyfunctional alcohol used to synthesize 


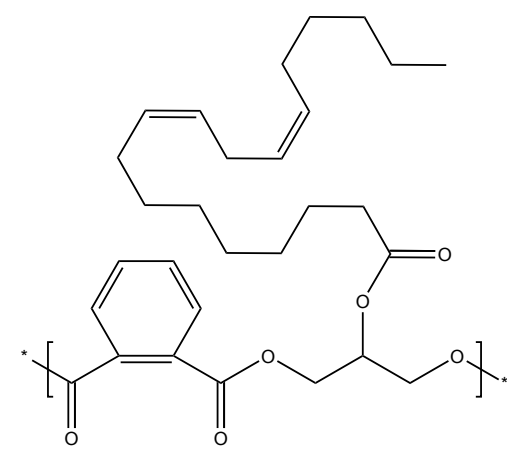

Figure 1: Model alkyd resin molecule showing the polyester backbone and a fatty acid chain.

the polyester backbone can vary and will influence the alkyd properties [4,5]. The types and distribution of fatty acids depend on the oil used in the production of the alkyd [6, 7]. Alkyd resins dry by both physical drying, where the solvent evaporates, and chemical curing, where oxygen from the atmosphere reacts with the double bonds in the drying oils and forms cross-links through radical reactions that increase the stiffness of the film. Other pathways result in scission of the chains and production of small volatile molecules. Many of these processes occur over very long periods of time. For example, Bartolozzi et al. showed that chemical changes took place over a period of months for a commercial alkyd formulation [8]. The oxygen uptake and radical initiation processes, however, begin on the time scales of hours. Peroxide values, calculated as peroxides per mass, reach a maximum within the first 24 hours for alkyds studied curing at room temperature [9]. Mechanistic studies on model systems, such as ethyl linoleate, show that over time, the concentration of carbon-carbon double bonds decreases and the number of cross-links, for instance, peroxide and ether linkages, increases $[3,10,11]$.

These studies used a variety of methods to study the chemical changes occurring in alkyd films throughout the curing process, but measuring the mechanical properties of paints from their initial application onto a substrate has proved challenging. Most traditional mechanical tests, including tensile tests, dynamic mechanical analysis, nanoindentation, and hardness tests can only measure films after through-drying has been achieved. Correlating mechanical and chemical changes occurring in these films would provide a more complete understanding of the behavior of alkyd resins and enable the calculation of mechanical properties from the predictions of chemical models.

Previous work relevant to the mechanical properties of alkyd resins comes from studies of both alkyd resins and linseed and other drying oils. Many aspects of the cure of alkyds are expected to be similar to these drying oils, since the cross-linking reactions that lead to curing occur in the fatty acid tails, which are present in both alkyds and pure drying oils. There will be some reactions unique to alkyds, however, related to the polyester backbone, such as the creation of free phthalic anhydride molecules upon aging as noted by Wei et al. [6]. Many studies have been done on the mechanical changes in linseed oil under various conditions, including measurements at elevated temperatures [12-14]. The earliest of these measurements of mechanical properties, however, are not until at least 65 days of drying. Tests showed that aging films at elevated temperatures resulted 
in a more rapid increase in modulus than curing at room temperature, although many studies have demonstrated that artificial aging at elevated temperature, while increasing stiffness and brittleness of the films, is not an accurate predictor of long-term properties of coatings [14, 15]. Studies of alkyd paints have confirmed that with aging, the glass transition temperature increases and there is an increase in the network density in the film $[1,16,17]$. These mechanical measurements, however, are unable to monitor the mechanical changes at short times, when significant chemical changes are occurring.

The quartz crystal microbalance (QCM) can measure properties of films in both liquid and solid states [18, 19], making it an ideal tool for systems such as alkyd paints that are initially very soft and become a glassy solid during the cure process. Capturing this wide range of properties is challenging using other mechanical techniques. The combination of mass and viscoelastic data that can be measured with the QCM also allows for a point of comparison with previous studies of alkyd curing, since mass is often measured during curing experiments $[14,20,21]$. The QCM has previously been used qualitatively to study alkyd resins during curing [22], and the feasibility of quantitative QCM studies of alkyd resins has been demonstrated $[19,23]$. No studies so far have correlated the mechanical changes at short times with chemical changes or shown continuous mechanical data from within minutes of film creation to years.

The present study uses a newly-developed rheometric application of the quartz crystal microbalance [19] to characterize the mechanical changes in alkyd resins under normal conditions over both short and long time scales, in addition to the more traditional use of the instrument as a mass sensing device. While other techniques such as rheometry or tensile tests will only work with samples that are liquid or solid respectively, the QCM can be used to measure systems that are changing state over the course of the measurements, which is important to the range of properties studied here. The effects of changes in oxygen concentration and temperature on the early stages of cure, starting from within minutes of the initial film application, were also studied. Since the measurements are non-destructive, the volume of the sample required for these measurements is small, and the samples are also available for measurements by a variety of other techniques. The conclusions were verified and interpreted by comparisons to Raman spectroscopy and dynamic mechanical analysis.

\section{Materials and Experimental Methods}

\subsection{Materials}

Alkyd films were prepared from Gamblin Artists Colors Galkyd. All samples were prepared from the same bottle as variations in the modulus and phase angle between bottles were observed in preliminary experiments. In preparing films for QCM, the alkyd was diluted 4:1 by weight in Gamsol odorless mineral spirits, also by Gamblin Artists Colors.

\subsection{Quartz Crystal Microbalance}

The quartz crystals used were standard polished AT-cut quartz crystals from Inficon with a thickness of $333 \mu \mathrm{m}$, a diameter of $25.4 \mathrm{~mm}$, and a fundamental resonant frequency, $f_{1}$, 
of $5 \mathrm{MHz}$. The electrodes were gold with a titanium adhesion layer. Impedance spectra were collected with either a N2PK Vector Network Analyzer or a Saunders \& Associates 250B network analyzer at the $1^{\text {st }}, 3^{\text {rd }}$, and $5^{\text {th }}$ harmonics $(5 \mathrm{MHz}, 15 \mathrm{MHz}$, and $25 \mathrm{MHz}$ ). Reference frequencies were measured individually for each crystal at the first three odd harmonics by taking measurements every 30 seconds for an hour. These measurements were repeated two more times for each crystal after removing and replacing the crystal in the holder. The reference frequencies and dissipation were taken as the average of these measurements and the uncertainty as the standard deviation. The peak fitting and calculations were done using in-house MATLAB programs using the solution method described previously $[18,19,24]$. Measured properties include the mass per area, normalized by the minimum value obtained after solvent evaporation, $\left|G_{3}\right| \rho$, the product of the density and magnitude of the complex shear modulus at $15 \mathrm{MHz}$, and $\phi$, the viscoelastic phase angle at $15 \mathrm{MHz}$. When error bars are not shown for these quantities, they were smaller than the symbol used in plotting. Although measurements were taken at the first three odd harmonics $(n=1,3,5)$, the calculations presented here show only the results calculated using $\Delta f_{1}, \Delta f_{3}$, and $\Delta \Gamma_{3}$., (referred to as the 1:3,3 calculation in our previous work $[19,24])$. We present the data this way because the 5 th harmonic was not able to be reliably measured during short experimental times, up to at least 10 hours depending on the thickness of the film. At longer times, there was good agreement between calculations made with the 1st, 3rd, and 5th harmonic, so for continuity only the 1:3,3 calculation is shown. Here $\Delta f_{n}$ and $\Delta \Gamma_{n}$ are the resonant frequency and bandwidth shifts respectively for the coated crystals relative to the uncoated crystals at the $n^{\text {th }}$ harmonic. Because the bandwidth of the resonance in the frequency domain is a measure of energy dissipation, we refer to the bandwidth as the 'dissipation' in much of what follows. Readers interested in the fundamentals of the QCM technique are referred to the excellent review article by Johannsmann [25]. Our implementation of the technique as a quartz crystal rheometer is described most thoroughly in reference [24].

The alkyd solutions were spun cast onto the quartz crystals using a Laurell model WS$650 \mathrm{MZ}-23 \mathrm{NPP}$ spin coater at $3000 \mathrm{rpm}$ with an acceleration of $200 \mathrm{rpm} / \mathrm{s}$ for a total time of 120 seconds, except for the room temperature samples with thicknesses of $3.11 \mu \mathrm{m}$ and $3.68 \mu \mathrm{m}$, which were spin coated for only 60 seconds. The initial time in the experiments is the end of the spin coating. The resultant films had thicknesses from 3-5 $\mu \mathrm{m}$ as determined by QCM measurements and confirmed for some samples with optical profilometry. Coated QCM crystals were placed in a holder and measurements were taken at intervals throughout the experiments. After at least three days of continuous measurements, or eight days in the case of temperature samples, samples were removed from the holders and stored in open boxes until being measured again. Samples cured under ambient conditions were exposed to the laboratory environment while curing (usually $22-23^{\circ} \mathrm{C}$ and $21-25 \% \mathrm{RH})$. Samples cured at elevated temperatures were placed in an oven at the specified temperature for a week, starting 10 minutes after the conclusion of spin coating. After a week in the oven, samples were removed from the oven and remained in ambient conditions for the rest of the experiment. The frequency shifts for measurements taken while at elevated temperatures were adjusted to account for the frequency shift of the bare quartz crystal with temperature, as described in reference [24]. These frequency 
corrections due to temperature changes were based on average measurements from three crystals at the different temperatures. No dissipation correction with temperature was needed. Data collected during the first thirty minutes after the samples were put in the oven and the first hour after removal from the oven were not used, as the frequency shift adjustment only applies after the quartz crystal and the holder have equilibrated to the temperature of the environment.

Samples cured under different partial pressures of oxygen were spun cast in the ambient atmosphere and placed within five minutes of the conclusion of spin coating into a sealed chamber under a flow of gas. The nitrogen used was UHP grade and the $8 \%$ oxygen gas was a mixture with nitrogen. The gas flow rate was reduced after two hours, but continued to flow throughout the exposure time. It was determined that no reference frequency correction was necessary for the slight increase in pressure resulting from the flow of gas for the atmospheric experiments.

\subsection{Dynamic Mechanical Analysis}

Samples for dynamic mechanical analysis were prepared by drawing down the undiluted alkyd resin using a Sheen film applicator with a gap of $0.42 \mathrm{~mm}$ on polystyrene film substrates with dimensions of $6 \mathrm{~cm}$ by $10 \mathrm{~cm}$. The final film thicknesses after solvent evaporation were 110-130 $\mu \mathrm{m}$. Films were removed from the polystyrene substrate after 21 days. The films were gently removed from the polystyrene after three weeks of curing and were allowed to relax for at least 9 weeks before the measurements were made. To prepare the samples for dynamic mechanical analysis, strips 4-6 mm wide and $>20 \mathrm{~mm}$ long were cut from the center of the films, which were the areas with the most consistent thickness. The strips were cut so the long dimension was in the same direction as the film applicator was drawn. Temperature-frequency data were collected with an RSA III dynamic mechanical analysis instrument (TA Instruments, New Castle, DE). The storage and loss tensile moduli were measured from $-75^{\circ} \mathrm{C}$ to $80^{\circ} \mathrm{C}$ in $5^{\circ} \mathrm{C}$ increments from $10 \mathrm{~Hz}$ to $0.1 \mathrm{~Hz}$. Ten points per decade were measured for 20 data points at each temperature.

To compare the Young's modulus measured by dynamic mechanical analysis with the shear modulus-density measured by QCM, Equation 1 was used assuming Poisson's ratio of 0.5 . This value is representative of rubbery polymers with $\left|G^{*}\right| \ll 10^{9} \mathrm{~Pa}$, and results in a relatively small error even for glassy polymers $\left(\left|G^{*}\right| \approx 10^{9} \mathrm{~Pa}\right)$ for which $v \approx 0.35$ [26]. The density of the alkyd resin in a film for dynamic mechanical analysis was measured from the volume and weight of a sample and was determined to be $1.2 \mathrm{~g} / \mathrm{cm}^{3}$.

$$
\left|G^{*}\right|=\frac{\left|E^{*}\right|}{2 \cdot(1+v)}
$$

\subsection{Raman Spectroscopy}

Raman spectra were collected from alkyd resin samples on silicon wafers prepared by the same method as the samples for QCM. Samples were measured on an Acton TriVista confocal Raman system with a wavelength of $514 \mathrm{~nm}$ and nominal power of $10 \mathrm{~mW}$. Spectra 
were collected as the average of 6 accumulations of 10 seconds each. Measurements from three different locations on the film were taken and averaged for each time point. Due to the thin nature of the films, which is on the order of the depth resolution for the confocal microscope, measurements were taken at the focus depth that maximized the signal from the film.

\section{Results and Discussion}

\subsection{Drying, Curing and Aging in Air}

(a)

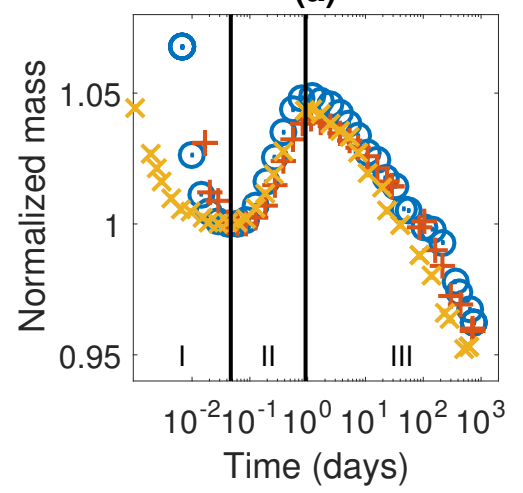

(b)

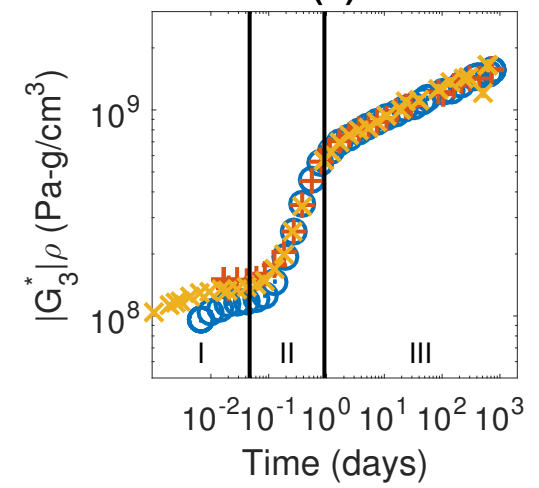

(c)

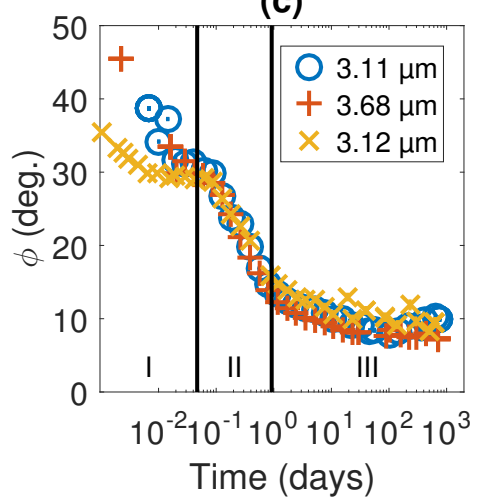

Figure 2: QCM data for room temperature curing of three alkyd samples as a function of time, from the first minutes to years of curing: (a) mass per area, (b) modulus-density and (c) phase angle. The legend shows the thickness in microns of each of the samples after solvent evaporation. The regions indicated by solid lines correspond to solvent evaporation (I), early stage curing (II) and long term curing (III).

Curing of an artists' alkyd resin was monitored with a quartz crystal microbalance from a couple minutes after film formation out to $\sim 2.5$ years. Figure 2 shows QCM data for three different alkyd samples curing in air. From left to right the plots show the normalized areal mass, the modulus-density product, and the phase angle. These results and the QCM results which follow are the calculations made with $\Delta f_{1}, \Delta f_{3}$ and $\Delta \Gamma_{3}$. We refer to calculations obtained from this combination of measure quantities as 1:3,3 calculations, and find that for these materials they are in good agreement with solutions found using other combinations of measured values [19]. The areal mass is normalized to the initial minimum which occurs after about one hour of curing. The initial minimum was chosen as the normalization value because this is the areal mass after solvent evaporation, that is, the initial mass of the polymer itself. Values of the magnitude of the complex shear modulus and the viscoelastic phase angle correspond to a measurement frequency of $15 \mathrm{MHz}$ in all cases.

The mass plot shows an initial rapid decrease in mass at very short times, followed by an increase in mass of about $4 \%$ and then a gradual decrease in mass that continues throughout the length of the experiment. The modulus-density plot shows that the modulus after some solvent evaporation is less than $1 \cdot 10^{8} \mathrm{~Pa}-\mathrm{g} / \mathrm{cm}^{3}$ and increases during the first 
couple of hours. The modulus then increases rapidly over the rest of the first day to $\sim 5.8 \cdot 10^{8} \mathrm{~Pa}-\mathrm{g} / \mathrm{cm}^{3}$, followed by a logarithmic increase which continues throughout the remainder of the measurements. After a year the modulus-density product for these samples was $\sim 1.4 \cdot 10^{9} \mathrm{~Pa}-\mathrm{g} / \mathrm{cm}^{3}$. The viscoelastic phase angle decreases during solvent evaporation and reaches a value of about 30 degrees by the completion of the solvent evaporation phase. The phase angle then decreases rapidly over the course of the first day of curing and then levels off after about three weeks to a value of 7-11 degrees.

Based on the observations from these three plots, three different regions can be identified, and the transitions are indicated in Figure 2 with black lines. They are easiest to distinguish on the plot of the normalized mass as they are delineated by the minimum and maximum in mass. The first region extends from film creation out to 60-90 minutes, when the minimum in mass occurs. The second region continues until 24-28 hours, when the maximum in the mass occurs. The third region extends from the maximum in mass out to at least two and a half years, which is as long as these measurements extend. Although these regions are initially defined with respect to the mass curve, they are also distinguished by changes in the behavior of the modulus and phase angle. The characteristics and chemical foundations of these three regions are discussed in more detail in the following sections.

\subsubsection{Solvent Evaporation}

In the first region, which extends from the beginning of the experiment to the time at which the mass is minimized, physical drying (solvent evaporation) is observed. In these samples, the solvent which is evaporating includes both the solvent included by the manufacturer in the resin to obtain the desired viscosity and the solvent added before spin coating to obtain the desired film thickness. In the three samples in Figure 2, two were spin coated for one minute and the last for two minutes. Longer spin coating resulted in less solvent loss measured by the QCM, so sample preparation has a large effect on the quantitative results in this first region. Since alkyd resins cure via both physical drying and oxidative cross-linking, the physical drying should be able to be observed by itself if no oxygen is present in the system. In order to separate out the competing effects on the mass of solvent evaporation and oxygen uptake, samples were placed under nitrogen and the properties monitored. Solvent evaporation occurs on short timescales-less than an hour. Focusing on just the first hour of curing, Figure 3 shows that the solvent evaporation process under nitrogen is complete about ten minutes after the end of spin coating. The sample curing in air has initial mass loss over a longer period, up to about 45 minutes, but the mass plateaus for a period at this point, suggesting that the mass loss due to solvent evaporation and the mass gain observed in air can be distinguished even in air. The more rapid evaporation of solvent under nitrogen may be a result of the active air flow through the sealed chamber. Noticeable oxygen uptake in the sample curing at room temperature as measured by an increase in mass does not occur until after 90 minutes of curing.

The changes in modulus and phase angle for both of the samples confirm that the solvent evaporation does have an effect on the mechanical properties of the film. The initial sharp 
(a)

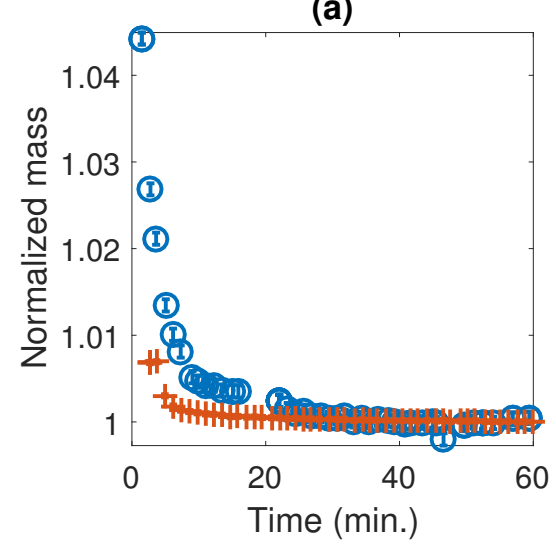

(b)

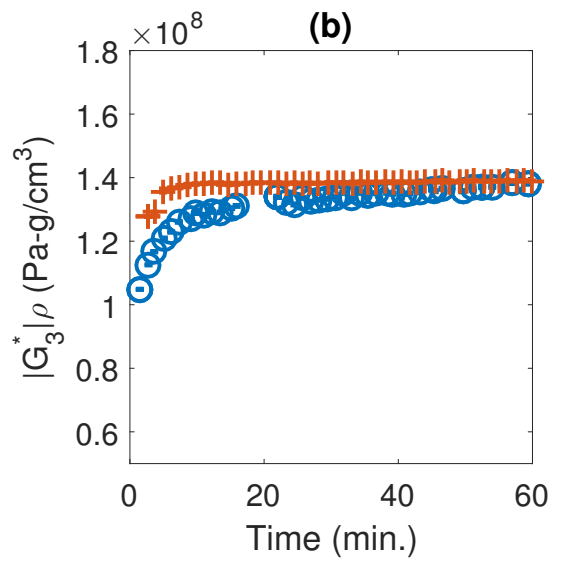

(c)

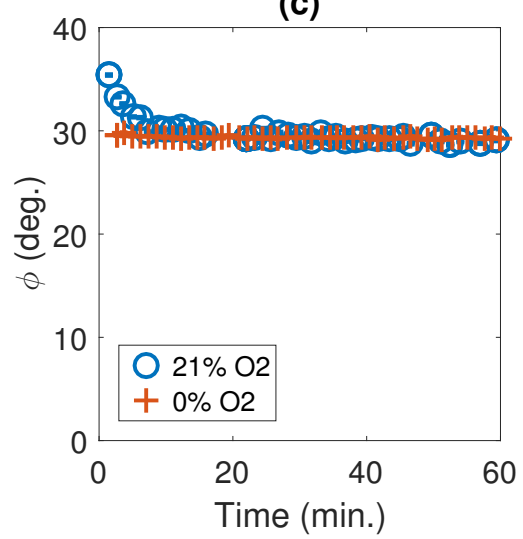

Figure 3: Comparison of QCM samples curing in air and under nitrogen for the first hour of curing.

decrease in mass is associated with a similarly rapid increase in modulus and decrease in phase angle. These changes are observed for samples in air and under nitrogen. The sample under nitrogen then experiences no further changes in modulus or phase angle until exposed to air. The sample in air has a small but steady increase in modulus, which may be the result of the longer solvent evaporation time or the beginning of cross-linking reactions not yet detectable in the mass changes. It is likely the former since the modulus after an hour is the same for both samples.

\subsubsection{Early Stage Curing}

The second region is that of mass gain due to oxygen uptake, which occurs between one hour and 24-28 hours. This period is associated with the most rapid changes in the modulus and phase angle. It is also during this time that the films become dry to the touch. Figure 4 narrows in on this region and the beginning of the third region, plotting the same data as is shown in Figure 2 but on a linear and restricted timescale. The increase in mass of $4-5 \%$ is consistent with the results of Mallégol et al., who saw maximum mass increases of 3.5-6.7\% for alkyds curing with various driers [21]; Lazzari and Chiantore, who observed a $7 \%$ increases in mass for linseed oil curing at elevated temperatures [20]; and Mecklenburg et al., who measured weight gains of almost $1 \%$ for linseed oil pigmented with lead carbonate [14]. This mass increase can be attributed to the presence of increased oxygen in the film during the early stages of oxidative crosslinking.

In order to understand how the mass increase and changes in modulus and phase angle correlate with chemical changes occurring in the resin, Raman spectra were collected for films during the first 100 hours of curing. Sample spectra from throughout this time are shown in Figure 5. In these spectra several peaks characteristic of alkyd resins are seen. The peaks at $1581 \mathrm{~cm}^{-1}$ and $1599 \mathrm{~cm}^{-1}$ correspond to aromatic carbon-carbon double bond stretches such as might be found in phthalic anhydride molecules [27]. The broad peak at $1725 \mathrm{~cm}^{-1}$ is attributed to the $\mathrm{C}=\mathrm{O}$ stretch in the ester of the polyester backbone [27]. Of the greatest interest during curing is what happens to the unconjugated double bonds, which can be seen in the stretch at $1655 \mathrm{~cm}^{-1}$, which corresponds to aliphatic 
(a)

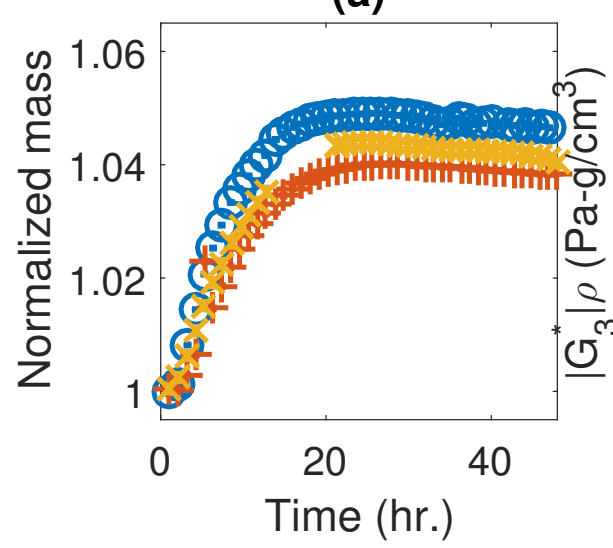

(b)

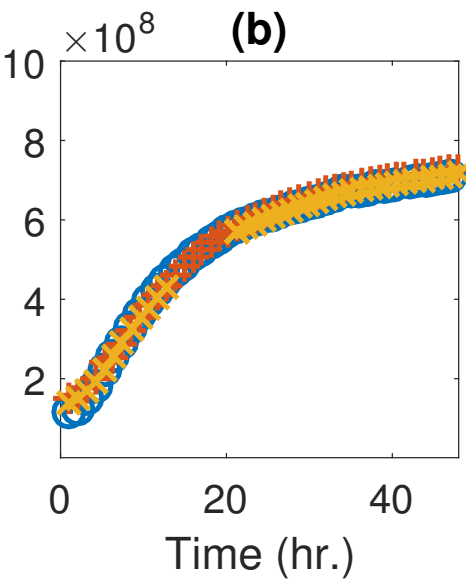

(c)

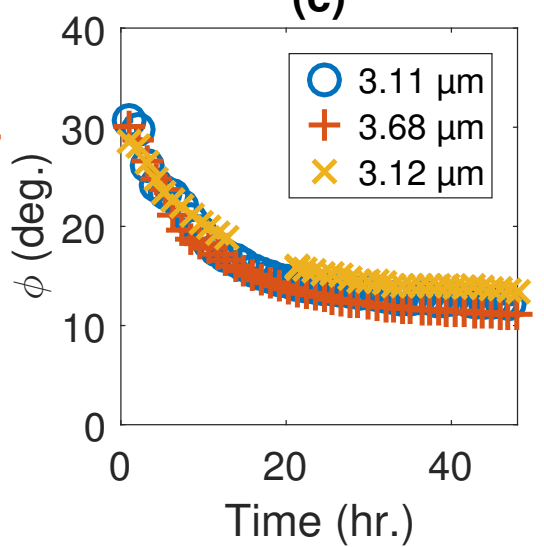

Figure 4: QCM data at short times. The samples are the same as in Figure 2.

cis carbon-carbon double bonds [11, 27-29], and the cis-CH=CH wag at $1265 \mathrm{~cm}^{-1}$ [30]. These double bonds are those found initially on the fatty acids and are the ones that participate in the cross-linking reactions. Both of these peaks decrease in intensity with time. The disappearance of these peaks over time is indicative of oxidation reactions proceeding [30,31]. Additionally, the broadening of the $1655 \mathrm{~cm}^{-1}$ band between 4 and 22 hours is to be attributed to chain modifications triggered by the formation of hydroperoxides, as it has also been observed for individual fatty acids [28]. The appearance of peaks at $1670 \mathrm{~cm}^{-1}$ and $1640 \mathrm{~cm}^{-1}$ have also been observed [28], and these are associated with trans and conjugated carbon-carbon double bonds that are produced by rearrangements after hydrogen abstraction. These peaks are only weakly observed in some of the spectra.

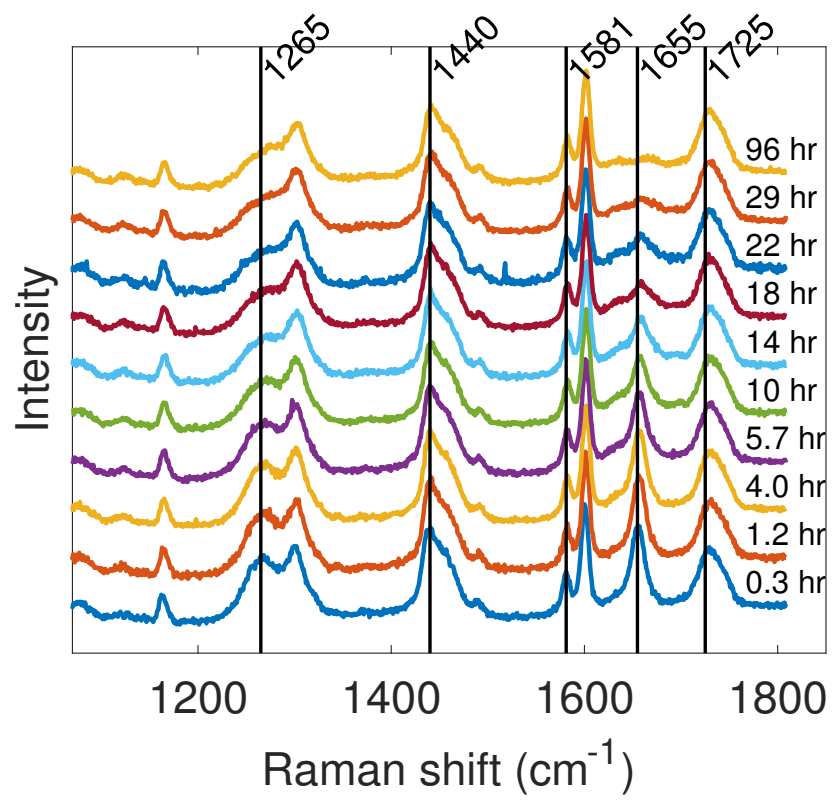

Figure 5: Raman spectra for alkyd resins during first 96 hours of curing

In order to quantify the change in the peak at $1655 \mathrm{~cm}^{-1}$ and correspondingly the progress 
of the reactions in the film, the peak intensity can be compared to peaks that should not be changing during curing by taking the ratios of the intensities [32]. Several peaks have been used as unchanging for references in studying drying oils. The $\mathrm{CH}_{2}$ deformation stretch at $1440 \mathrm{~cm}^{-1}$ is associated with the saturated parts of the fatty acid tails [27, 28] The peak at $1725 \mathrm{~cm}^{-1}$ corresponds to the $\mathrm{C}=\mathrm{O}$ in the polyester backbone [33]. Lastly, the aromatic carbon-carbon double bond stretch at $1599 \mathrm{~cm}^{-1}$ arises from the phthalic acid in the polyester backbone [34]. Although other peaks can be used, the reference peaks at $1440 \mathrm{~cm}^{-1}$ and $1599 \mathrm{~cm}^{-1}$ were chosen since both peaks and the peak at $1655 \mathrm{~cm}^{-1}$ can be measured within a single scan, thereby preserving the relative peak intensities. The ratios of the intensity of the peak at $1655 \mathrm{~cm}^{-1}$ to the peaks at $1440 \mathrm{~cm}^{-1}$ and $1599 \mathrm{~cm}^{-1}$ with time are shown in Figure 6.

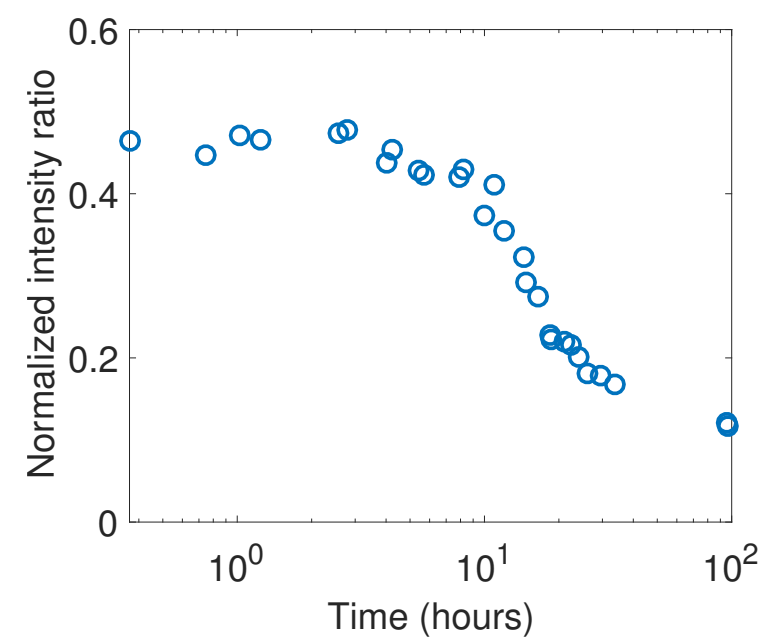

(a) $1655 \mathrm{~cm}^{-1} / 1440 \mathrm{~cm}^{-1}$

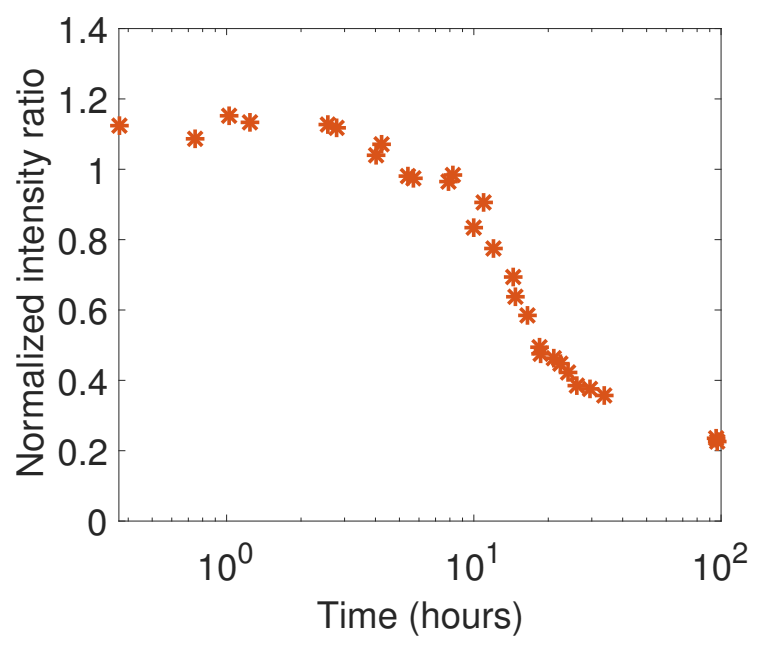

(b) $1655 \mathrm{~cm}^{-1} / 1599 \mathrm{~cm}^{-1}$

Figure 6: Ratios of the intensities of the specified Raman peaks with time on a log scale. Each point is the average of three measurements taken at different locations on the film.

The plots shown in Figure 6 show that the number of cis double bonds does not decrease much initially. The intensity ratios remain steady for at least two hours, and do not begin decreasing rapidly until around ten hours of curing. By 30 hours after film formation, the intensity of the peak is less than half of the original value. The shape of the curves are similar to those observed by Agbenyega et al. [28] for methyl linolenate, a model for alkyds, and Ellis et al. [27] for alkyd resins pigmented with titanium dioxide. Both studies observed an initial period of a steady or increasing ratio of the $1655 \mathrm{~cm}^{-1}$ peak to an unchanging peak followed by a rapid decrease in the ratio with changes continuing for longer times, as observed here.

These Raman data confirm that in this second region, significant chemical changes are occurring in the film. The Raman spectra corroborate the trends identified with the QCM mass data, confirming that the first few hours of curing are dominated by physical drying linked to solvent evaporation. The double bonds continue to decrease with time beyond 24 hours, so these ratios do not show a distinct chemical marker related to double bond disappearance and the end of the second region at $24-28$ hours. This is an indication that 
even when oxygen uptake reaches a plateau due to diffusion rate limitations as evidenced in the normalized mass plot of Figure 2, radical reaction, chain rearrangements, chain scission and cross-linking reactions continue inside the film. The shape of these Raman band intensity ratio curves is similar to that of the phase angle. A direct comparison shows that the plateau is slightly longer for the ratios of the Raman peaks than the phase angle, but both properties have completed the large decrease by the end of the second region.

This second period, between the end of solvent evaporation and the beginning of the film losing mass, is characterized by significant and rapid changes in the mass, modulus, phase angle, and double bond concentration in the film. Since alkyds are complex systems with many reactions proceeding at the same time, from the data presented here it is not possible to correlate the decrease in double bond concentration with a particular change in the physical properties of the film, although there are similarities with the phase angle. However, with the detailed early-stage viscoelastic data presented in this paper, supplemented with additional chemical data and a model of the curing process it may become feasible to correlate the mechanical properties of the alkyd film with the chemical state.

\subsubsection{Long-term Curing}

The third region begins after about a day of curing and continues for years. This region is characterized by mass loss, a logarithmic increase in the modulus, and a plateauing phase angle. After a year the samples had lost about 3\% mass relative to the initial minimum observed and $7 \%$ relative to the maximum in the mass. This mass loss after the mass gain is consistent with other studies of both alkyd resins and linseed oils [14, 20, 21]. Mecklenburg and Tumosa observed increases in the mass of linseed oil films with time, even out to times of years, but also observed that the mass gain was less than the theoretical mass gain possible resulting from oxygen uptake [13]. Other studies, however, found that linseed oil films reached a maximum mass within several days of curing and then began losing mass $[14,20]$. This mass loss is the result of the formation of volatile products from oxidation reactions $[35,36]$.

It is in this region that comparisons can be made with dynamic mechanical analysis [37] because the films are stiff enough to be free-standing. The logarithmic increase in modulus is consistent with the increase in stress for linseed oil films observed by Mecklenburg and Tumosa [13]. To compare mechanical properties at particular times for the specific alkyd resin studied here, a direct comparison to rheological data obtained at lower frequencies with more conventional techniques was made. Films for dynamic mechanical analysis were removed from the substrates after three weeks, and were measured after 84, 103, and 159 days. Figure 7 shows the time-temperature superposition results for alkyd films of different ages. In (a), the modulus increases with frequency and plateaus at high frequencies. The high-frequency modulus also increases as a function of curing time. Figure 7 (b) shows the phase angle with frequency and peaks in the phase angle are observed at reference frequencies around $0.1 \mathrm{~Hz}$. The peak in the phase angle shifts to higher frequencies with increased curing time. Figure 7 (c) shows the temperature dependence of the shift factors used to generate the master curves shown in parts a and $b$ of Figure 7. 

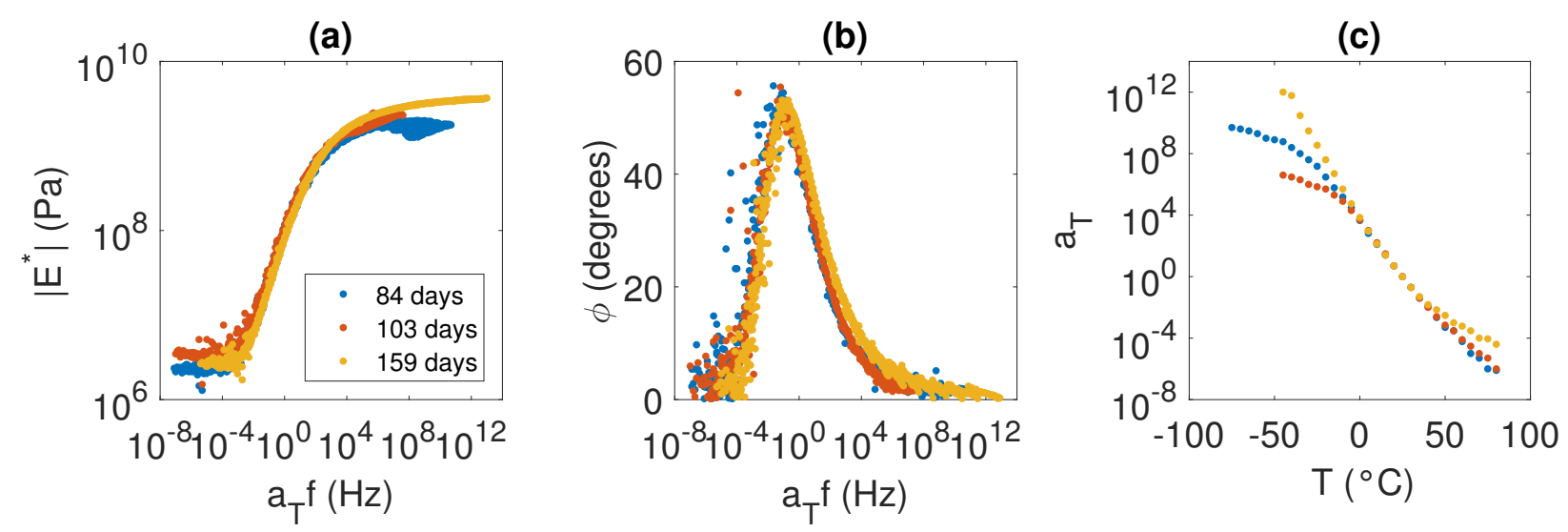

Figure 7: Time-temperature superposition results for alkyd films at 84 days, 103 days, and 159 days with a reference temperature of $25^{\circ} \mathrm{C}$. (a) shows the absolute value of the Young's modulus as a function of the frequency multiplied by the shift factor $a_{T}$. (b) shows the phase angle as a function of the frequency multiplied by the shift factor $a_{T}$. (c) shows the values of the shift factor $a_{T}$ as a function of temperature.

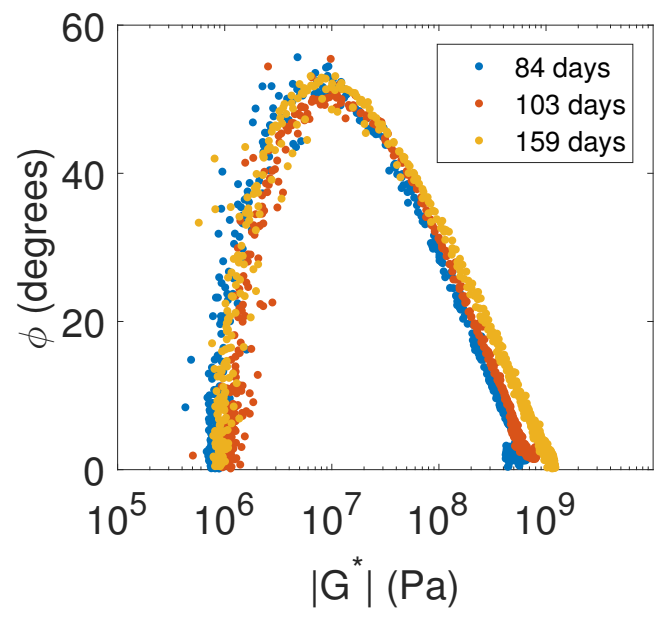

Figure 8: Van Gurp-Palmen plot of DMA data for an alkyd resin aged 84, 103, and 159 days.

Figure 8 shows how the modulus and phase angle are related to one another for the full range of dynamic mechanical data. Plotting the data on a van Gurp-Palmen plot such as this removes the details of the time-temperature superposition and enables easy comparison of material properties without concern for frequency [38, 39]. As the films age the high-frequency modulus increases, as can be seen by the shifts to higher moduli in the lower right of the plot. Figure 9 shows a comparison between the dynamical mechanical (low-frequency) and QCM (high-frequency) data at 159 days. The modulus-density product obtained from the QCM was converted to a modulus by assuming a density of $1.2 \mathrm{~g} / \mathrm{cm}^{3}$, obtained from the volume and mass of a dynamic mechanical analysis sample.

The QCM data had a higher phase angle and modulus than the dynamic mechanical data for the same frequency. The film thickness may account for some of this difference. The dynamic mechanical analysis samples were 110-130 $\mu$ m thick, while the QCM samples 
(a)

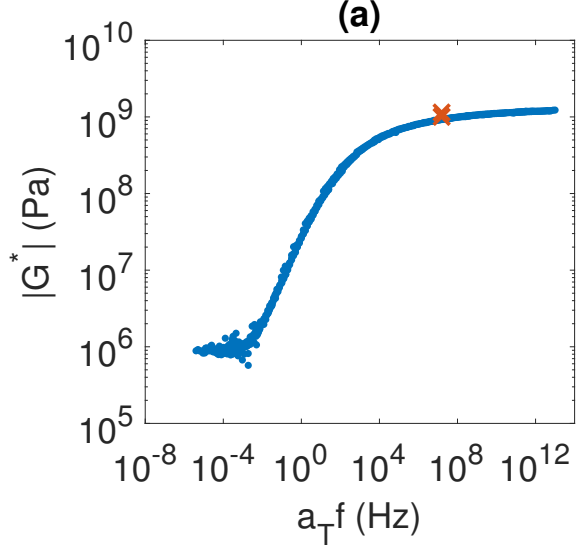

(b)

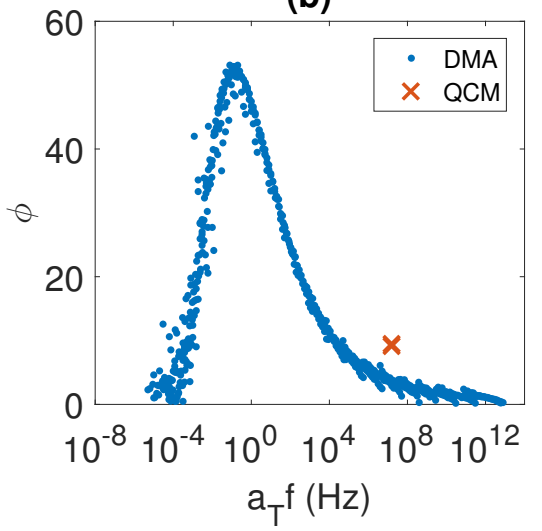

Figure 9: Modulus and phase angle from dynamic mechanical data and QCM data at 159 days.

were 3-5 $\mu \mathrm{m}$ thick. Several studies have looked at alkyd chemistry with thickness over time and found gradients in properties with increased thickness [16, 21, 29, 34, 40-43]. However, Marton et al. [29] and Mirone et al. [42] found that for long oil alkyds, both solvent and water-borne, the first $10 \mu \mathrm{m}$ of the film is homogeneous with respect to the chemical properties measured. This means that on the length scales of the film for QCM measurements, the film can be assumed to be homogeneous, but also that the properties measured will be most representative of the surface of a film. In the dynamic mechanical samples, then, the film properties may not be homogeneous, with the middle being softer than the surfaces. While this can explain the higher modulus of the QCM samples, since the phase angle decreases with curing, a film cured all the way through would have a lower phase angle, rather than a higher one. The difference between the QCM modulus and phase angle and that measured by dynamic mechanical analysis may rather reflect a breakdown in time-temperature superposition due to the large difference in the frequencies at which the measurements were taken. The dynamic mechanical data was collected at a maximum of $10 \mathrm{~Hz}$, while the QCM data was at $15 \mathrm{MHz}$. A similar difference between dynamic mechanical and QCM moduli and phase angles has previously been observed for systems that were heterogeneous on a nanometer length scale [44].

While dynamic mechanical analysis is able to provide data over a wide range of frequencies, it is limited in its ability to provide meaningful results in the early stages of the cure process. Taking individual time points with dynamic mechanical analysis is also a more time and material intensive process, as a measurement at a single time point requires a new piece of film to be measured and the temperature and frequency sweeps to be obtained. While the QCM is limited to measurements at a single frequency, it yields time-dependent data from a single sample. This capability is very useful in studying the long-term aging of a sample, but one must keep in mind that the mechanical response being probed corresponds to a very high frequency, or equivalently, to a very short time, $\sim 100$ nanoseconds for the frequency used in our experiments. This difference in time scale needs to be accounted for when interpreting the QCM results. From Figure 9 (a), for example, we see that the modulus of our sample measured by the QCM is a factor 
of 100 larger than the modulus that would be obtained from an experiment, such as a nanoindentation, where the material is probed over a time scale of $\sim 1$ second.

\subsection{Effect of Oxygen}

The experiments to separate physical drying from oxidative curing discussed earlier showed the importance of oxygen in initiating the cross-linking process leading to the formation of a solid film. Another set of experiments was done to look more particularly at whether the concentration of oxygen in the atmosphere is a limiting factor in these reactions. To investigate this, alkyd films were placed in an environment with $8 \%$ oxygen and the remainder nitrogen, a substantial depletion of oxygen in comparison to air, which contains $21 \%$ oxygen. The samples were placed in this environment within five minutes of being spun cast. Figure 10 shows the differences between a sample cured in air, a sample cured in the more limited oxygen atmosphere, and a sample under nitrogen. After the initial few minutes, the sample under nitrogen does not change significantly, as solvent evaporation is the primary mechanism of changes in the mechanical properties in the absence of oxygen. The sample curing in air, however, shows a mass increase of about $4 \%$, a significant increase in the modulus, and a decrease in the phase angle. The sample in a reduced oxygen atmosphere has a similar mass increase to the sample curing in air, but the peak is at a later time. Rather than occurring between 24 and 28 hours as was observed for samples curing in air, the maximum occurred around 32 hours. The modulus increased more slowly than in air as well. While eliminating oxygen completely stopped the oxidative curing process, reducing the amount of oxygen present slowed the curing process slightly.

(a)

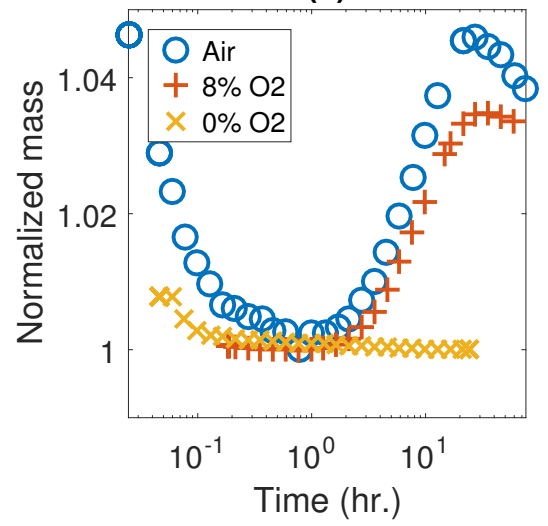

(b)

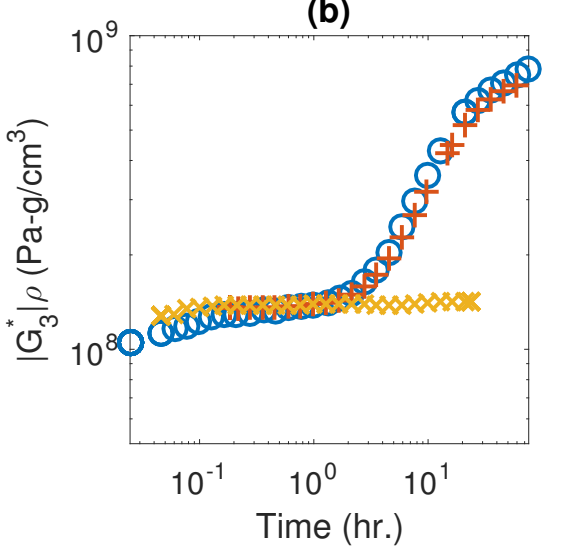

(c)

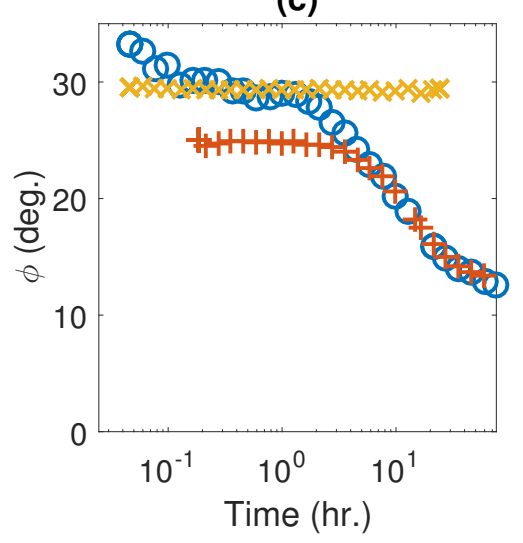

Figure 10: Comparison of samples curing in air $\left(21 \% \mathrm{O}_{2}\right)$ and $8 \% \mathrm{O}_{2}$ as a function of $\log$ time.

\subsection{Effect of Temperature}

Curing of alkyd resin samples was carried out at different temperatures in order to better understand the kinetics of the process and to evaluate the effect that different regimes of artificial thermal aging have on the mechanical properties of alkyd films. Samples were kept at elevated temperatures for one week and then returned to room temperature. Figure 11 (a) shows mass data for representative samples at each temperature. The shaded 
region in the middle of the plot indicates when the samples were exposed to higher temperatures, and the temperatures themselves are shown in the legend. The mass data are normalized to the maximum in the mass because the minimum in the mass, which represents the mass of the film after solvent evaporation, occurred while the samples were equilibrating to the higher temperature. This period of missing data occurs because the temperature correction to the reference frequency and dissipation can only be applied after the sample and holder have reached the new temperature. There is no gap in the data at room temperature because no correction is needed. Each of the samples shows some initial mass loss, followed by a mass increase. The samples then exhibit a maximum in the mass that occurs at shorter times for higher temperatures. The maxima are observed at around one hour at $80^{\circ} \mathrm{C}$ and 25 hours at $23^{\circ} \mathrm{C}$. The maximum in mass is followed by a steady decrease in mass up to the point of removal from the oven.

Each of the samples has a mass curve of similar shape. As a result the curves can be superimposed by dividing the experiment times for each of the samples by a fixed temperaturedependent factor, $c_{t}$. With $c_{t}$ set to be equal to unity at room temperature, the superposition curves shown in Figure 11 (b) were obtained, confirming that the shape of the mass increase is similar for all of these samples. Note that the mass decreases at short times do not superpose. This initial mass decrease corresponds to an evaporation process rather than a curing process, and is therefore characterized by a different temperature shift factor. Figure 11 (c) shows the reciprocal time shift factor, $1 / c_{t}$, as a function of the reciprocal temperature.

(a)

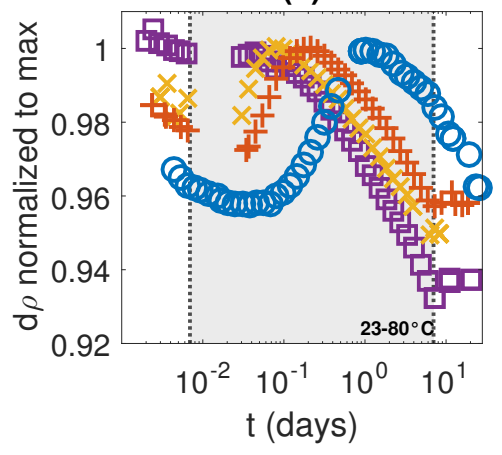

(b)

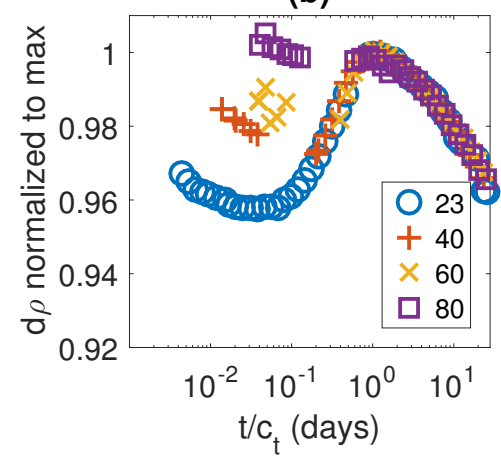

(c)

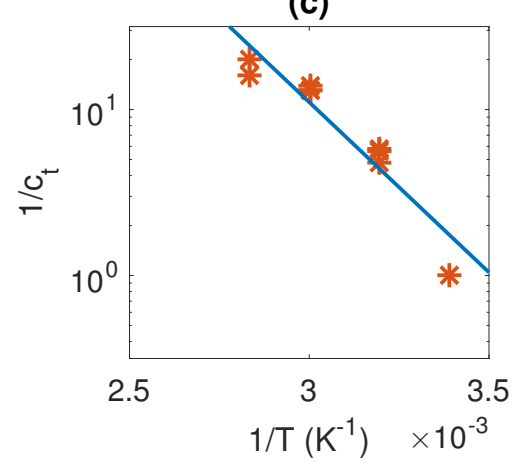

Figure 11: (a) Normalized mass data for representative samples at each temperature as a function of log time from 0 to 28 days. The shaded region indicates the times when the samples were exposed to the specified temperatures. The regions either side were at room temperature. (b) Normalized mass data shifted by a factor $1 / c_{t}$. (c) Reciprocal shift factors, $c_{t}$, as a function of 1 /temperature.

Assuming that the shift in the mass curves can be used as a marker for the rate of the overall reaction, the effective activation energy for the first stage of the oxidative curing process can be obtained. This is not the activation energy for a particular process, but rather the overall rate for the processes occurring during these initial stages of curing including the induction period, oxygen uptake, and cross-linking. The line in Figure 11 (c) shows the Arrhenius relationship between the time shift factor and the temperature. Using the standard Arrhenius relationship, and assuming that $1 / c_{t}$ is proportional to the 
overall rate of reaction, the slope of this line gives an estimate of the effective activation energy for the curing process of $4.1 \mathrm{kcal} / \mathrm{mol}(17 \mathrm{~kJ} / \mathrm{mol})$.

Since polymers have temperature dependent properties, it is not constructive to compare the modulus and phase angle of the film at room temperature with the films at elevated temperatures while curing is occurring. The moduli can be compared, however, after the samples have been returned to room temperature. The data points shown in Figure 12a were measured 12 hours after the samples were removed from the oven to give them sufficient time to equilibrate to room temperature. There is a significant increase in modulus with curing temperature. This is as expected since the rate of curing increased as discussed previously and the modulus increases with curing as was observed for the room temperature samples.
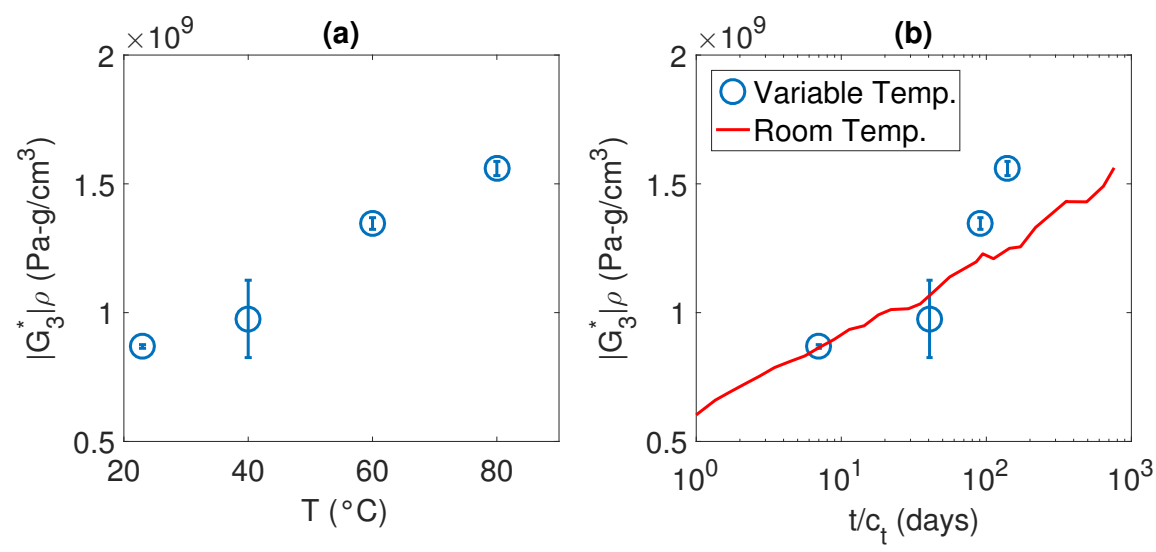

Figure 12: (a) Density-modulus product after one week of curing at different temperatures. (b) The same data plotted as a function of $t / c_{t}$ (symbols), compared to the room temperature data at long times from Figure 2.

We conclude with a final word of caution concerning the use of elevated temperatures as a protocol for accelerated aging of these types of materials. It is clear from the results shown in Figures 11 and 12 that the processes leading to mass loss and an increase in modulus are both accelerated at higher temperatures. However, the temperature dependences of these two processes is not identical. This difference is illustrated in Figure 12 (b). where the density-modulus product is plotted against the normalized time, $t / c_{t}$, using the values of $c_{t}$ determined from the mass superposition. Higher temperatures accelerate increases in $\left|G_{3}\right| \rho$ more than they accelerate the mass loss, indicating that the final state of the material obtained during a thermal annealing treatment cannot be mapped onto any material state obtained by aging at room temperature. The higher temperature changes the relative rates of different processes, giving a final material with properties that depend on temperature and time in a way that does not allow the effects of these two variables to be separated. Many of the properties of highly aged paints and coatings can only be addressed by suitably realistic kinetic models of describing the rate-dependent reactions that take place during the aging process. The real power of the QCM technique developed here is that it can provide a rich data set for the development of predictive molecular models that can be applied outside the experimentally accessible window of aging times. 


\section{Conclusions}

The viscoelastic properties of an alkyd resin have been monitored in real time with the quartz crystal microbalance. The curing of the alkyds was divided into three regimes, corresponding to physical drying, early stage curing and late stage curing.

- Physical Drying: This regime corresponds to evaporation of solvent from the film, and occurs during the first hour after the film is cast. During this time, there is little change in the modulus or phase angle at the measurement frequency of $15 \mathrm{MHz}$.

- Early-Stage Curing: This regime, taking place from 1-24 hours after film casting, is characterized by an increase of about $4 \%$ in the mass of the film and by significant increases in the modulus. By the end of this region most of the cis double bonds originally present in the resin have either disappeared or rearranged to the trans conformation, as determined by Raman spectroscopy.

- Long-Term Curing This region is characterized by a logarithmic increase in the modulus and a plateauing of the phase angle, and continues out to time scales of years.

The same three regions were observed at higher temperatures, with the onset of each region occurring at shorter times as the temperature increased. These measurements enabled the estimation of the overall free energy of activation for the curing process of 4.1 $\mathrm{kcal} / \mathrm{mol}$.

In summary, this work represents an extensive application of the QCM to the study of alkyd resins, an important medium for both the arts and the coatings industry. Direct measurement of the film mechanical properties over time demonstrates the value of the QCM as a quantitative tool for investigating the kinetics of the cure process.

\section{Acknowledgments}

This material is based upon work supported by the National Science Foundation through the Division of Materials Research (DMR-1241667) and through the Graduate Research Fellowship program (DGE-1324585). The Andrew W. Mellon Foundation and Stockman Family Foundation are thanked for their support of scientific research at the Art Institute of Chicago. This work made use of the Keck-II facility of the NUANCE Center at Northwestern University, which has received support from the Soft and Hybrid Nanotechnology Experimental (SHyNE) Resource (NSF NNCI-1542205); the MRSEC program (NSF DMR-1121262) at the Materials Research Center; the International Institute for Nanotechnology (IIN); the Keck Foundation; and the State of Illinois, through the IIN.

[1] R. Ploeger, D. Scalarone, O. Chiantore, Thermal analytical study of the oxidative stability of artists' alkyd paints, Polymer Degradation and Stability 94 (11) (2009) 2036-2041. doi:10.1016/j.polymdegradstab. 2009.07.018. 
[2] T. Learner, G. C. Institute, Analysis Of Modern Paints, Getty Publications, 2005.

[3] R. van Gorkum, E. Bouwman, The oxidative drying of alkyd paint catalysed by metal complexes, Coordination Chemistry Reviews 249 (17-18) (2005) 1709-1728. doi:10. 1016/j.ccr.2005.02.002.

[4] T. A. Misev, Calculating technique for formulating alkyd resins, Prog. Org. Coat. 21 (1) (1992) 79-99. doi:10.1016/0033-0655(92)80013-M.

[5] S. Aydin, H. Akçay, E. Özkan, F. S. Güner, A. T. Erciyes, The effects of anhydride type and amount on viscosity and film properties of alkyd resin, Prog. Org. Coat. 51 (4) (2004) 273-279. doi:10.1016/j . porgcoat. 2004.07.009.

[6] S. Wei, V. Pintus, M. Schreiner, A comparison study of alkyd resin used in art works by Py-GC/MS and GC/MS: The influence of aging, Journal of Analytical and Applied Pyrolysis 104 (2013) 441-447. doi:10.1016/j . jaap. 2013.05.028.

[7] J. La Nasa, I. Degano, F. Modugno, M. P. Colombini, Alkyd paints in art: Characterization using integrated mass spectrometry, Anal. Chim. Acta 797 (2013) 64-80. doi:10.1016/j.aca.2013.08.021.

[8] G. Bartolozzi, V. Marchiafava, V. Mirabello, M. Peruzzini, M. Picollo, Chemical curing in alkyd paints: An evaluation via FT-IR and NMR spectroscopies, Spectrochim. Acta, Part A 118 (2014) 520-525. doi:10.1016/j.saa.2013.09.017.

[9] J. Mallégol, L. Gonon, S. Commereuc, V. Verney, Thermal (DSC) and chemical (iodometric titration) methods for peroxides measurements in order to monitor drying extent of alkyd resins, Prog. Org. Coat. 41 (1-3) (2001) 171-176. doi:10.1016/ S0300-9440 (01) 00144-8.

[10] W. Muizebelt, J. Hubert, R. Venderbosch, Mechanistic study of drying of alkyd resins using ethyl linoleate as a model substance, Prog. Org. Coat. 24 (1-4) (1994) 263-279. doi:10.1016/0033-0655(94)85019-4.

[11] Z. O. Oyman, W. Ming, R. van der Linde, Oxidation of model compound emulsions for alkyd paints under the influence of cobalt drier, Prog. Org. Coat. 48 (1) (2003) 80-91. doi:10.1016/S0300-9440(03)00119-X.

[12] J. D. Erlebacher, E. Brown, M. F. Mecklenburg, C. S. Tumosa, The Effects of Temperature and Relative Humidity on the Mechanical Properties of Modern Painting Materials, Materials Issues in Art and Archaeology III; symposium held April 27-May 1, 1992, San Francisco, California 267 (1992) 359-370. doi:10. 1557/PROC-267-359.

[13] M. F. Mecklenburg, C. S. Tumosa, Traditional Oil Paints: The Effects of Long-Term Chemical and Mechanical Properties on Restoration Efforts, MRS Bulletin 26 (01) (2001) 51-54. doi : 10.1557/mrs2001. 19. 
[14] M. Mecklenburg, C. Tumosa, D. Erhardt, The changing mechanical properties of aging oil paints, Materials Issues in Art and Archaeology VII 852 (2004) 13-24. doi:10.1557/PROC-852-003.1.

[15] D. Erhardt, C. Tumosa, M. Mecklenburg, Natural and Accelerated Thermal Aging of Oil Paint Films, in: Studies in Conservation, Vol. 45, Melbourne, 2000, pp. 65-69. doi:10.1179/sic.2000.45. Supplement-1.65.

[16] S. J. F. Erich, J. Laven, L. Pel, H. P. Huinink, K. Kopinga, NMR depth profiling of drying alkyd coatings with different catalysts, Prog. Org. Coat. 55 (2) (2006) 105-111. doi:10.1016/j. porgcoat. 2005.08.009.

[17] S. J. F. Erich, J. Laven, L. Pel, H. P. Huinink, K. Kopinga, Influence of catalyst type on the curing process and network structure of alkyd coatings, Polymer 47 (4) (2006) 1141-1149. doi:10.1016/j.polymer.2005.12.081.

[18] G. C. DeNolf, L. Haack, J. Holubka, A. Straccia, K. Blohowiak, C. Broadbent, K. R. Shull, High Frequency Rheometry of Viscoelastic Coatings with the Quartz Crystal Microbalance, Langmuir 27 (16) (2011) 9873-9879. doi:10.1021/la200646h.

[19] L. Sturdy, F. Casadio, M. Kokkori, K. Muir, K. R. Shull, Quartz crystal rheometry: A quantitative technique for studying curing and aging in artists' paints, Polymer Degradation and Stability 107 (2014) 348-355. doi:10.1016/j. polymdegradstab. 2014.02.009.

[20] M. Lazzari, O. Chiantore, Drying and oxidative degradation of linseed oil, Polymer Degradation and Stability 65 (2) (1999) 303-313. doi :10.1016/S0141-3910 (99) 00020-8.

[21] J. Mallégol, A. M. Barry, E. Ciampi, P. M. Glover, P. J. McDonald, J. L. Keddie, M. Wallin, A. Motiejauskaite, P. K. Weissenborn, Influence of drier combination on through-drying in waterborne alkyd emulsion coatings observed with magnetic resonance profiling, Journal of Coatings Technology 74 (933) (2002) 113-124. doi:10.1007/BF02697951.

[22] A.-C. Hellgren, M. Wallin, P. Weissenborn, P. McDonald, P. Glover, J. Keddie, New techniques for determining the extent of crosslinking in coatings, Prog. Org. Coat. 43 (1-3) (2001) 85-98. doi : 10 .1016/S0300-9440(01)00215-6.

[23] A. L. Smith, Using Quartz Crystal Microbalance-Heat Conduction Calorimetry to Monitor the Drying and Curing of an Alkyd Spray Enamel, in: P. Zarras, T. Wood, B. Richey, B. C. Benicewicz (Eds.), New Developments in Coatings Technology, Vol. 962, American Chemical Society, Washington, DC, 2007, pp. 261-277.

[24] G. C. DeNolf, L. F. Sturdy, K. R. Shull, High-Frequency Rheological Characterization of Homogeneous Polymer Films with the Quartz Crystal Microbalance, Langmuir 30 (32) (2014) 9731-9740. doi:10.1021/1a502090a. 
[25] D. Johannsmann, Viscoelastic, mechanical, and dielectric measurements on complex samples with the quartz crystal microbalance, Phys. Chem. Chem. Phys. 10 (31) (2008) 4516-4534.

[26] I. Ward, D. Hadley, An Introduction to the Mechanical Properties of Solid Polymers, Wiley, New York, 1993.

[27] G. Ellis, M. Claybourn, S. Richards, The application of fourier transform raman spectroscopy to the study of paint systems, Spectrochim. Acta, Part A 46 (2) (1990) 227241. doi : 10.1016/0584-8539(90)80092-D.

[28] J. K. Agbenyega, M. Claybourn, G. Ellis, A study of the autoxidation of some unsaturated fatty acid methyl esters using Fourier transform Raman spectroscopy, Spectrochim. Acta, Part A 47 (9-10) (1991) 1375-1388. doi:10.1016/0584-8539(91) 80228-B.

[29] B. Marton, L. G. van der Ven, C. Otto, N. Uzunbajakava, M. A. Hempenius, G. J. Vancso, A depth-resolved look at the network development in alkyd coatings by confocal Raman microspectroscopy, Polymer 46 (25) (2005) 11330-11339. doi:10. $1016 / j$. polymer . 2005.10.021.

[30] Z. O. Oyman, W. Ming, R. v. d. Linde, Oxidation of drying oils containing nonconjugated and conjugated double bonds catalyzed by a cobalt catalyst, Prog. Org. Coat. 54 (3) (2005) 198-204. doi : 10.1016/j jporgcoat.2005.06.004.

[31] S. Higuchi, T. Hamada, Y. Gohshi, Examination of the Photochemical Curing and Degradation of Oil Paints by Laser Raman Spectroscopy, Appl. Spectrosc., AS 51 (8) (1997) 1218-1223. doi:10.1366/0003702971941782.

[32] T. Jawhari, P. J. Hendra, H. A. Willis, M. Judkins, Quantitative analysis using Raman methods, Spectrochim. Acta, Part A 46 (2) (1990) 161-170. doi:10.1016/ 0584-8539(90)80086-E.

[33] S. J. F. Erich, J. Laven, L. Pel, H. P. Huinink, K. Kopinga, Comparison of NMR and confocal Raman microscopy as coatings research tools, Prog. Org. Coat. 52 (3) (2005) 210-216. doi:10.1016/j. porgcoat.2004.12.002.

[34] Z. Oyman, W. Ming, R. Van Der Linde, J. Ter Borg, A. Schut, J. Bieleman, Oxidative drying of alkyd paints catalysed by a dinuclear manganese complex (MnMeTACN), Surface Coatings International Part B: Coatings Transactions 88 (4) (2005) 269-275. doi:10.1007/BF02699583.

[35] J. Mallégol, J.-L. Gardette, J. Lemaire, Long-term behavior of oil-based varnishes and paints. I. Spectroscopic analysis of curing drying oils, Journal of the American Oil Chemists' Society 76 (8) (1999) 967-976.

[36] E. Bouwman, R. Gorkum, A study of new manganese complexes as potential driers for alkyd paints, J Coat Technol Res 4 (4) (2007) 491-503. doi:10.1007/ s11998-007-9041-0. 
[37] R. F. Landel, L. E. Nielsen, Mechanical Properties of Polymers and Composites, Second Edition, 2nd Edition, CRC Press, New York, 1993.

[38] van Gurp, J. Palmen, Time-Temperature Superposition for Polymeric Blends, Rheol. Bull. 67 (1998) 5-8.

[39] S. Trinkle, C. Friedrich, Van Gurp-Palmen-plot: a way to characterize polydispersity of linear polymers, Rheol. Acta 40 (4) (2001) 322-328. doi:10.1007/s003970000137. URL http://link. springer.com/article/10.1007/s003970000137

[40] J. Mallégol, L. Gonon, J. Lemaire, J. L. Gardette, Long-term behaviour of oil-based varnishes and paints 4 . Influence of film thickness on the photooxidation, Polymer Degradation and Stability 72 (2) (2001) 191-197. doi :10.1016/S0141-3910(00) $00170-1$.

[41] J. Laven, U. Aravind, R. Van Der Linde, The chemical drying process in alkyd emulsion paint films, in: Proceedings of the 29th International Conference of Coatings Science and Technology, Athens, Greece, 2003, pp. 201-218.

[42] G. Mirone, B. Marton, G. J. Vancso, Elastic modulus profiles in the cross sections of drying alkyd coating films: modelling and experiments, European Polymer Journal 40 (3) (2004) 549-560. doi:10.1016/j . eurpolymj .2003.10.017.

[43] S. J. F. Erich, J. Laven, L. Pel, H. Huinink, K. Kopinga, Dynamics of cross linking fronts in alkyd coatings, Applied Physics Letters 86 (13) (2005) 134105-134105-3. doi:10.1063/1.1886913.

[44] C. J. Yeh, M. Dowland, R. G. Schmidt, K. R. Shull, Fracture and thermal aging of resin-filled silicone elastomers, J. Polym. Sci. Part B: Polym. Phys. 54 (2) (2016) 263273. doi:10.1002/polb. 23919. 


\section{Alkyd}

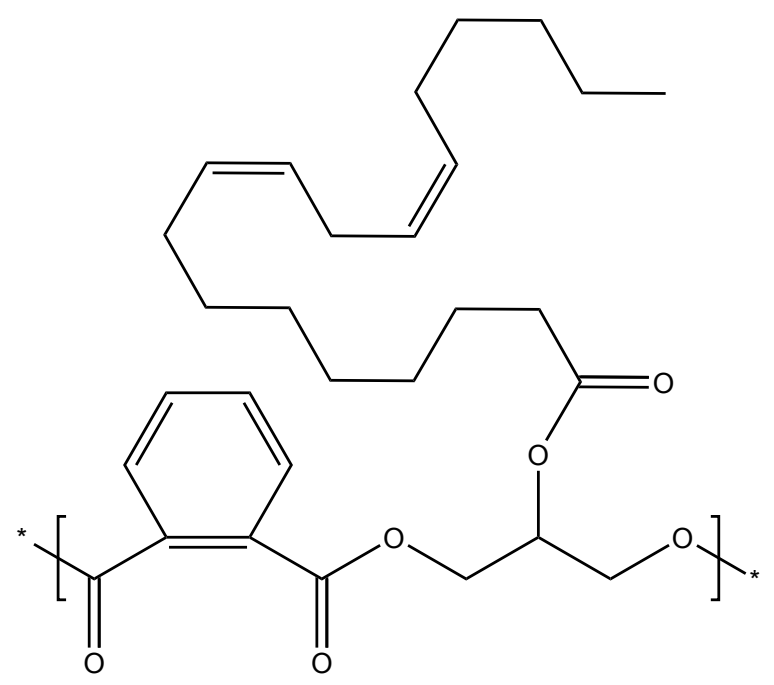

Quartz Crytal Microbalance

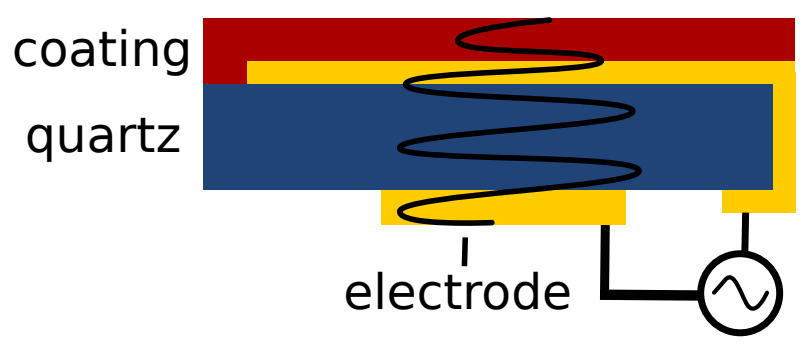

